\title{
Ictal autonomic changes as a tool for seizure detection: a systematic review
}

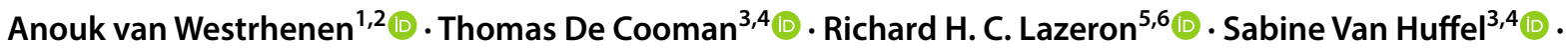 \\ Roland D. Thijs ${ }^{1,2}$ (D)
}

Received: 29 August 2018 / Accepted: 7 October 2018 / Published online: 30 October 2018

(c) The Author(s) 2018

\begin{abstract}
Purpose Adequate epileptic seizure detection may have the potential to minimize seizure-related complications and improve treatment evaluation. Autonomic changes often precede ictal electroencephalographic discharges and therefore provide a promising tool for timely seizure detection. We reviewed the literature for seizure detection algorithms using autonomic nervous system parameters.

Methods The PubMed and Embase databases were systematically searched for original human studies that validate an algorithm for automatic seizure detection based on autonomic function alterations. Studies on neonates only and pilot studies without performance data were excluded. Algorithm performance was compared for studies with a similar design (retrospective vs. prospective) reporting both sensitivity and false alarm rate (FAR). Quality assessment was performed using QUADAS-2 and recently reported quality standards on reporting seizure detection algorithms.

Results Twenty-one out of 638 studies were included in the analysis. Fifteen studies presented a single-modality algorithm based on heart rate variability $(n=10)$, heart rate $(n=4)$, or QRS morphology $(n=1)$, while six studies assessed multimodal algorithms using various combinations of HR, corrected QT interval, oxygen saturation, electrodermal activity, and accelerometry. Most studies had small sample sizes and a short follow-up period. Only two studies performed a prospective validation. A tendency for a lower FAR was found for retrospectively validated algorithms using multimodal autonomic parameters compared to those using single modalities (mean sensitivity per participant $71-100 \%$ vs. 64-96\%, and mean FAR per participant $0.0-2.4 / \mathrm{h}$ vs. $0.7-5.4 / \mathrm{h}$ ).

Conclusions The overall quality of studies on seizure detection using autonomic parameters is low. Unimodal autonomic algorithms cannot reach acceptable performance as false alarm rates are still too high. Larger prospective studies are needed to validate multimodal automatic seizure detection.
\end{abstract}

Keywords Automatic seizure detection - Autonomic function(s) - Autonomic parameter(s) - Algorithm(s) - Epilepsy · SUDEP

Electronic supplementary material The online version of this article (https://doi.org/10.1007/s10286-018-0568-1) contains supplementary material, which is available to authorized users.

Roland D. Thijs

rthijs@sein.nl

1 Stichting Epilepsie Instellingen Nederland (SEIN), Heemstede, P.O. Box 540, 2130 AM Hoofddorp, The Netherlands

2 Department of Neurology, Leiden University Medical Center (LUMC), Leiden, The Netherlands

3 Department of Electrical Engineering (ESAT), STADIUS Center for Dynamical Systems, Signal Processing and Data Analytics, KU Leuven, Louvain, Belgium
4 IMEC, Louvain, Belgium

5 Academic Center of Epileptology Kempenhaeghe, Heeze, The Netherlands

6 Faculty of Electrical Engineering, Technical University Eindhoven, Eindhoven, The Netherlands 


\section{Introduction}

Epileptic seizures are potentially dangerous as they can lead to complications, including injury, status epilepticus, and sudden unexpected death in epilepsy (SUDEP) [1]. Adequate seizure detection may have the potential to minimize these complications and to ameliorate treatment evaluation, as seizures - particularly those at night — are often underreported [2-5]. Detection devices may also help to improve the independence and quality of life of people with epilepsy and their caregivers $[3,6]$.

Several parameters, including movement, sound, and autonomic nervous system changes, can be used to detect seizures. This review focuses on changes in autonomic function, including cardiovascular, respiratory, and transpiration changes [7]. Seizures can alter autonomic function, particularly if the central autonomic network is involved. The most common expression is a sudden increase in sympathetic tone $[7,8]$. Ictal tachycardia (IT) is a very frequent sign, with prevalence rates ranging from 80 to $100 \%$ [9, 10]. IT is a hallmark of convulsive seizures (i.e., focal to bilateral tonic-clonic as well as generalized tonic-clonic seizures), and more common in temporal lobe vs. extratemporal lobe seizures [9]. Changes in autonomic function can precede ictal electroencephalographic (EEG) discharges by several seconds [10-12]. Preictal tachycardia has an incidence rate of approximately one-third of seizures [13]. Autonomic alterations may therefore provide an adequate tool for early seizure detection and facilitate timely interventions. Ictal arrhythmias and desaturations are more common but are thought to be self-limiting, while postictal arrhythmias and apneas may lead to SUDEP [14-17]. SUDEP usually occurs several minutes after a convulsive seizure (mean $10 \mathrm{~min}$, range 2-17 $\mathrm{min}$ ) [18]. Raising an alarm at seizure onset may be sufficient to allow timely intervention.

We aimed to systematically review different seizure detection algorithms based on autonomic function changes.

\section{Methods}

This systematic review was conducted in accordance with the preferred reporting items for systematic reviews and meta-analyses (PRISMA) guideline [19].

The PubMed and Embase databases were systematically searched through May 2018 for original studies validating an algorithm for automatic seizure detection based on heart rate (HR), heart rate variability (HRV), oxygen saturation (SpO2), electrodermal activity (EDA, reflecting changes in transpiration), or a combination of the aforementioned. A sequence of synonyms for 'autonomic variables,' 'seizures,' and 'detection' were used as search terms (see Table S1 in the Electronic supplementary material, ESM). Studies were included if they met the following criteria: (1) human studies; (2) written in English; (3) reporting on children or adults with any type of epilepsy; (4) validating an algorithm for automatic seizure detection using autonomic parameters; (5) reporting at least one performance measure [sensitivity, positive predictive value (PPV), false alarm rate (FAR), or detection latency (DL)]. Studies on neonates only were excluded, because both seizure and autonomic function characteristics differ greatly at this age compared to older age. Pilot studies lacking performance data, as well as conference abstracts and reviews were also excluded (Fig. 1).

One author (AvW) screened all titles and abstracts, as well as the full texts of the remaining studies. For each article included, the following parameters were recorded: method of automatic seizure detection, type of autonomic variable, individual characteristics, number and types of seizures analyzed, prospective or retrospective validation, total recording time and performance of the algorithm (including sensitivity, PPV, FAR, and DL). We compared algorithm performance using multimodal autonomic parameters versus those using single modalities, provided that the studies (1) had a similar design (prospective vs. retrospective) and (2) reported both sensitivity and FAR.

The quality of the included studies was evaluated using the QUADAS-2 [20]. This tool consists of four domains (patient selection, index test, reference standard, and flow and timing) and different signaling questions to assist in judgments of the risk of bias and applicability. Additionally, we assessed all included studies according to the recently proposed standards for clinical validation of seizure detection devices (SDDs) [21].

\section{Results}

Out of the 638 articles identified, 86 studies were selected on the basis of title and abstract. After full-text screening, 21 studies were included for further analysis. Most of the excluded articles lacked the validation of a seizure detection algorithm (see Fig. 1). The characteristics of the included studies are summarized in Table 1. Most of the studies $(n=15)$ focused on ictal cardiac changes as a tool for seizure detection algorithms, including HRV $(n=10)$ [8, 22-30], HR $(n=4)$ [31-34], and changes in QRS morphology $(n=1)$ [35]. Six studies used multimodal algorithms, including combinations of HR, corrected QT interval (QTc), SpO2, EDA, and accelerometry (ACC) [2, 36-40]. None of the included studies validated an algorithm based on oxygen saturation or EDA alone. Most studies were conducted in adults, but two studies included a pediatric population [23, 40], and six studies included both children and adults [22, 25, 35-37, 39]. Fourteen studies prospectively enrolled their 


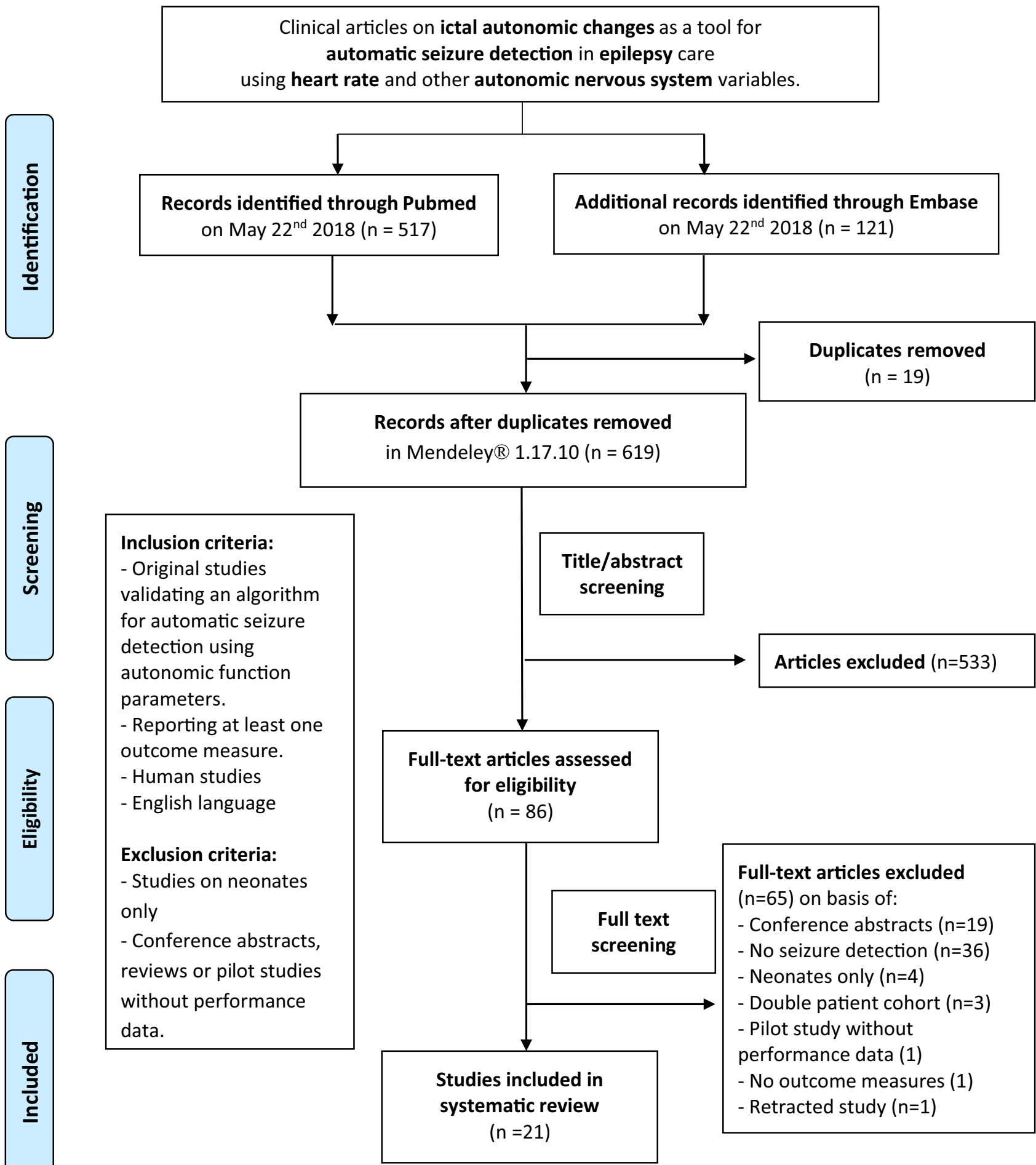

Fig. 1 Flowchart of the search for applicable studies

participants $[8,22,23,26,28,30-33,36-40]$, but only two studies prospectively validated their algorithm [31, 33].

Most studies had small sample sizes (median population size 14, IQR 7-26). The number of seizures analyzed per patient tended to be low (median number of seizures per participant 3, IQR 2-7). The total recording time used to validate the algorithm varied from $7 \mathrm{~min}$ to $158 \mathrm{~h}$ per person (median recording time per participant $34 \mathrm{~h}$, IQR 


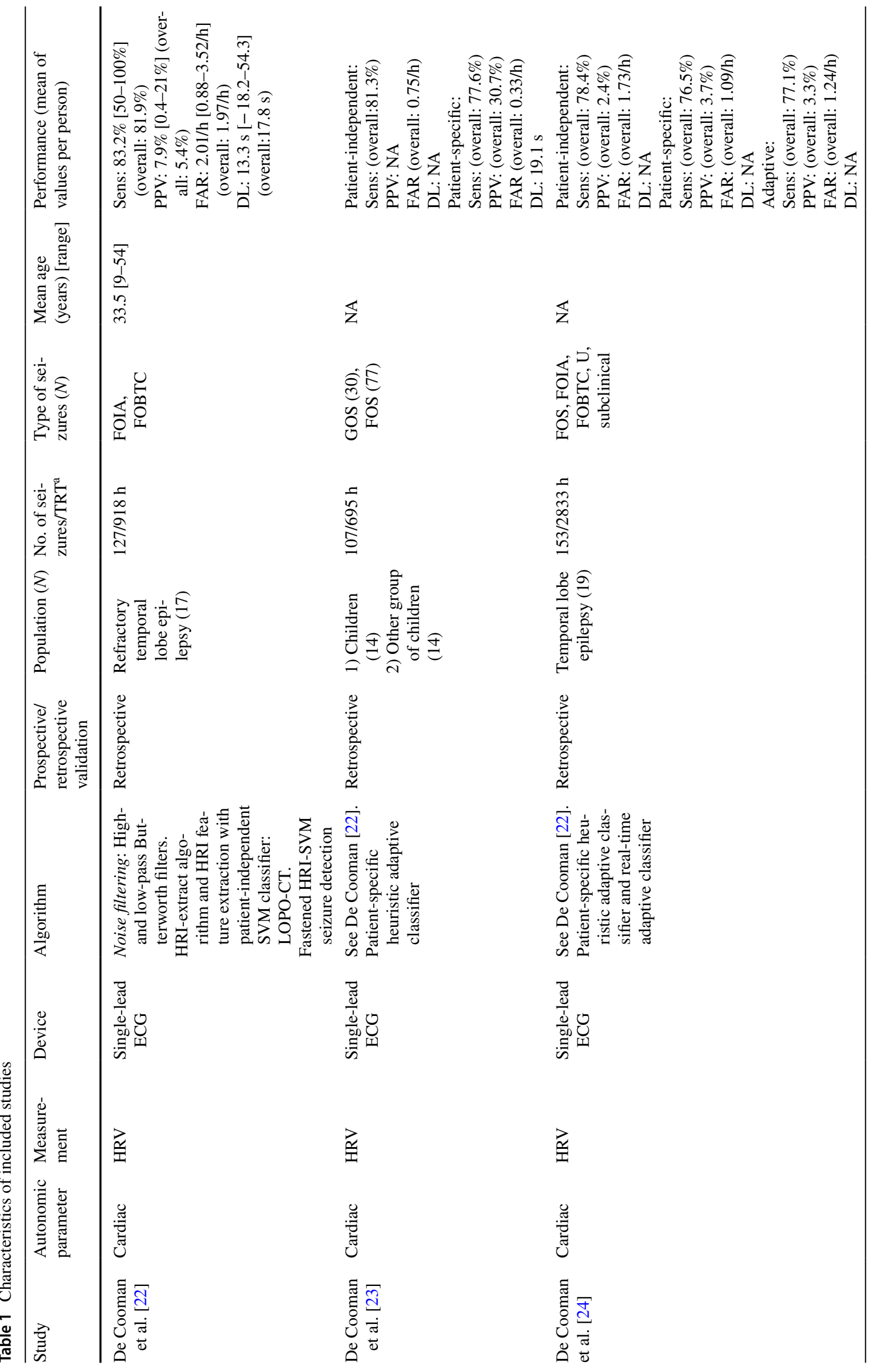




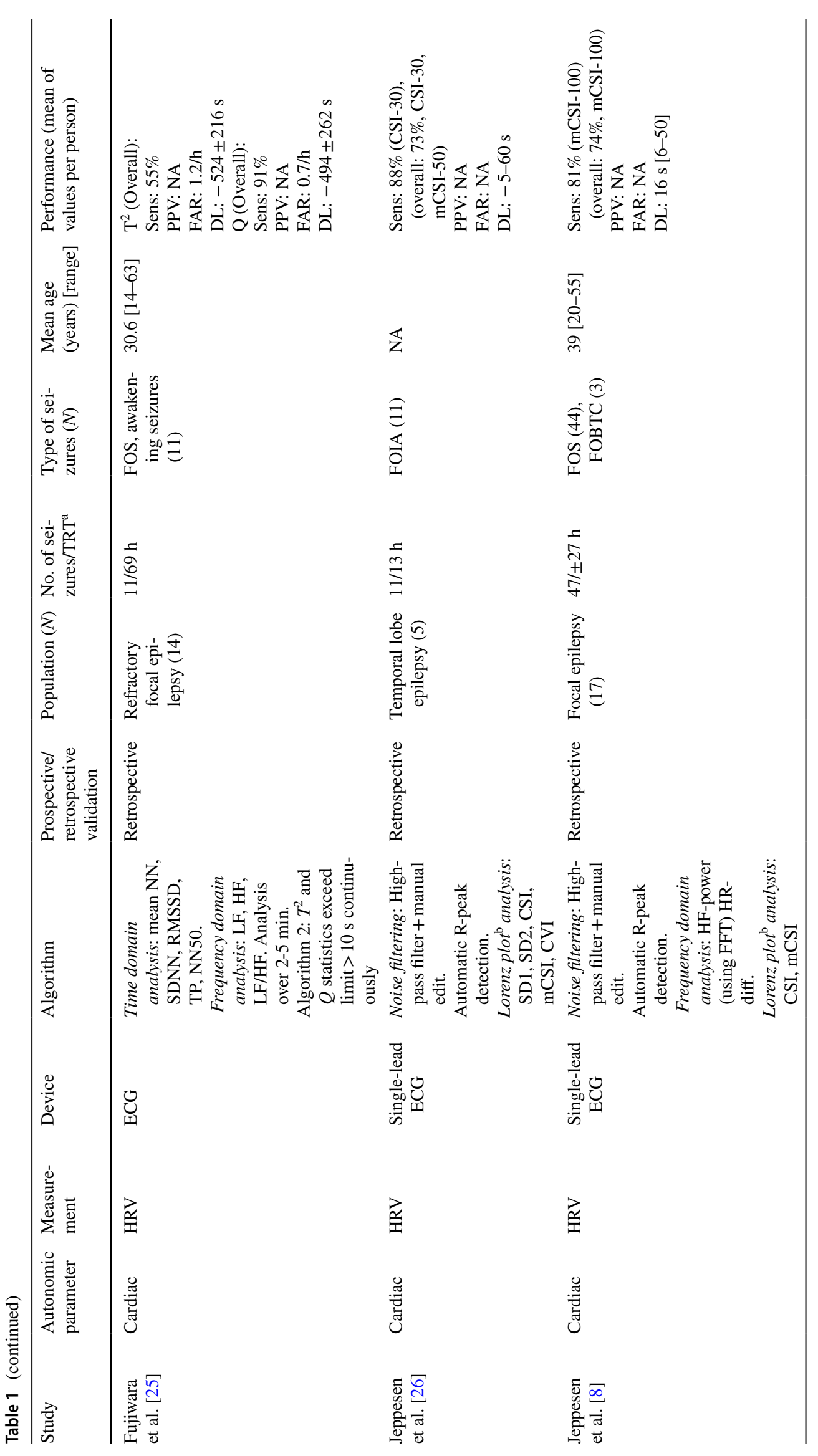




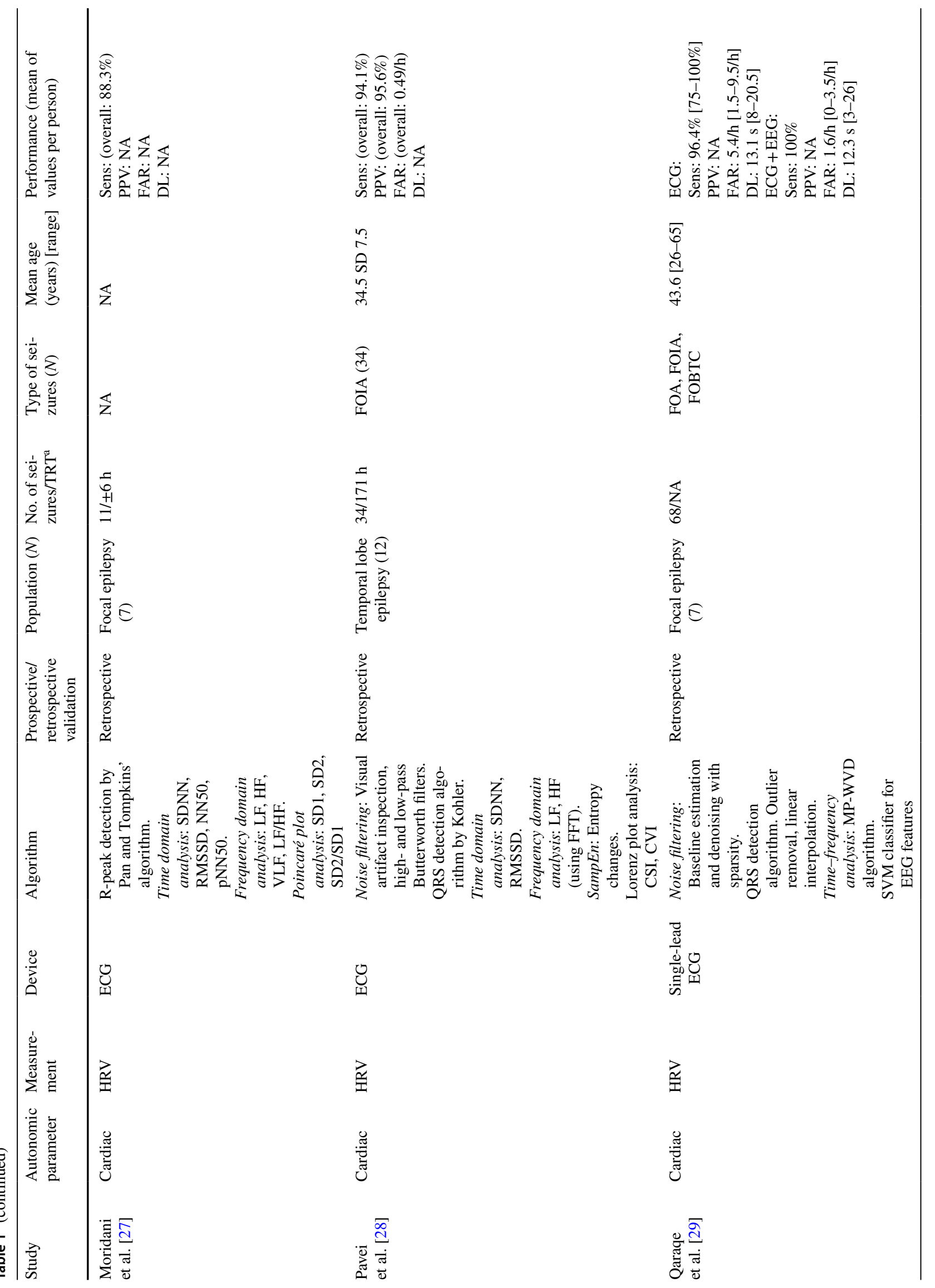


Clinical Autonomic Research (2019) 29:161-181

167

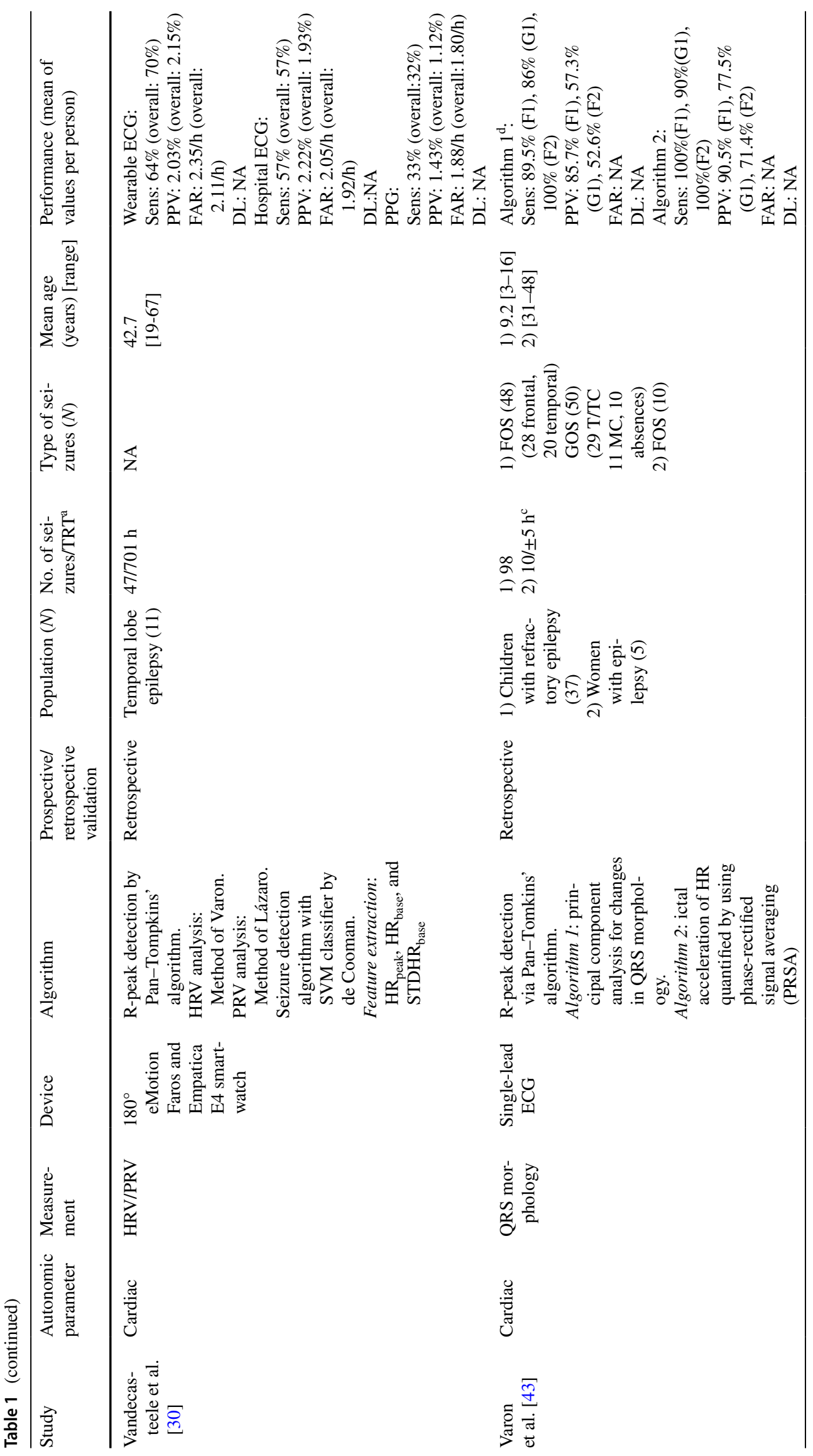

Springer 


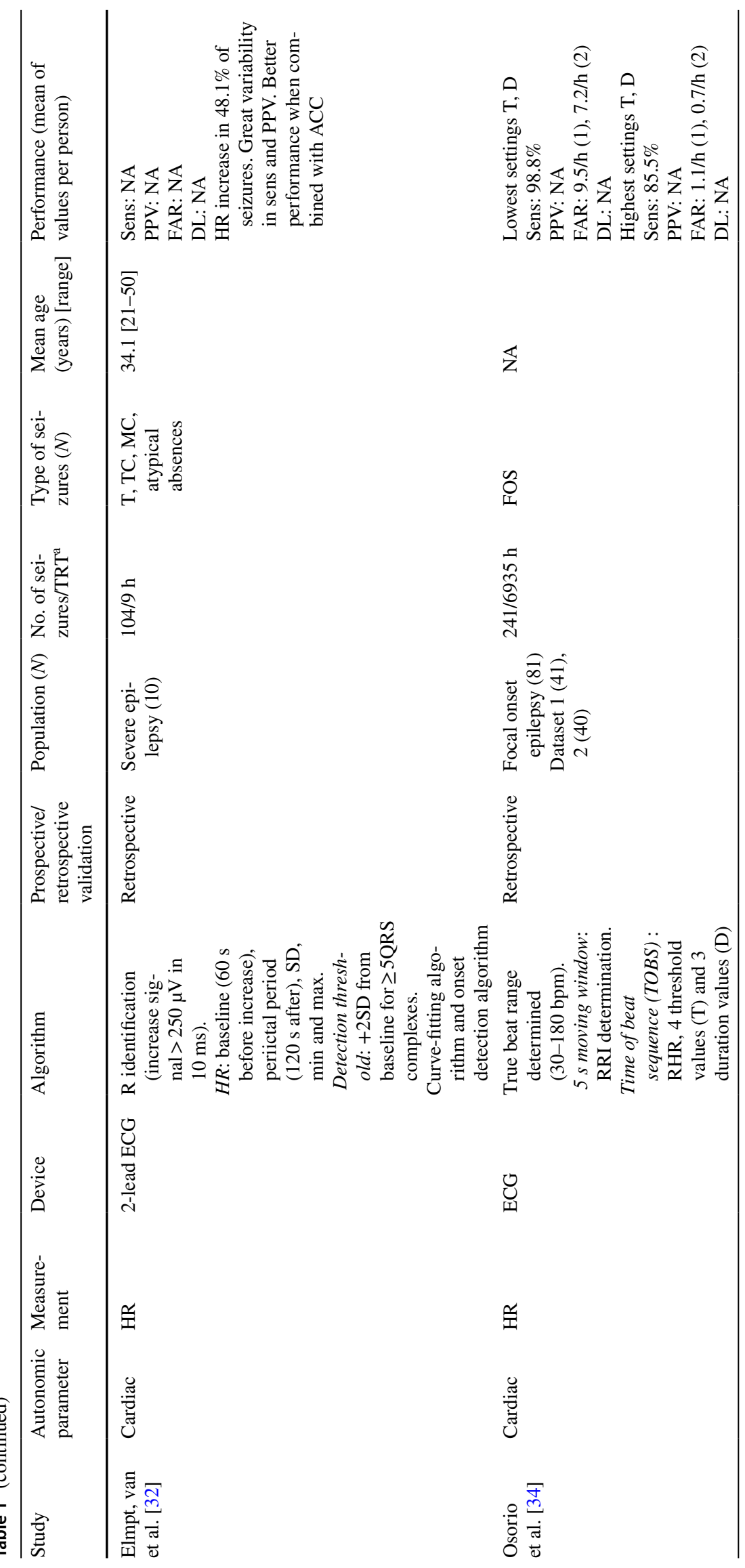




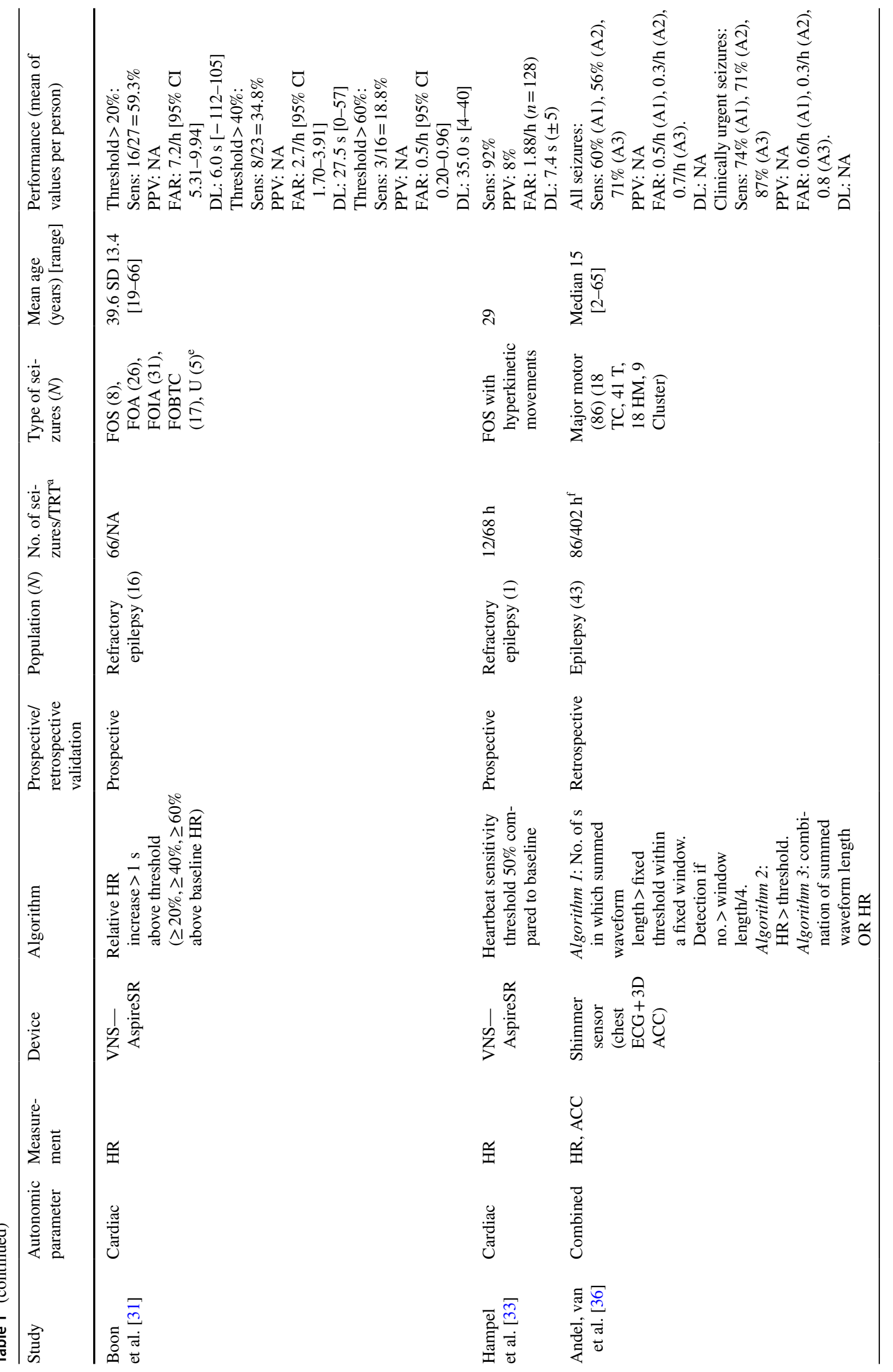




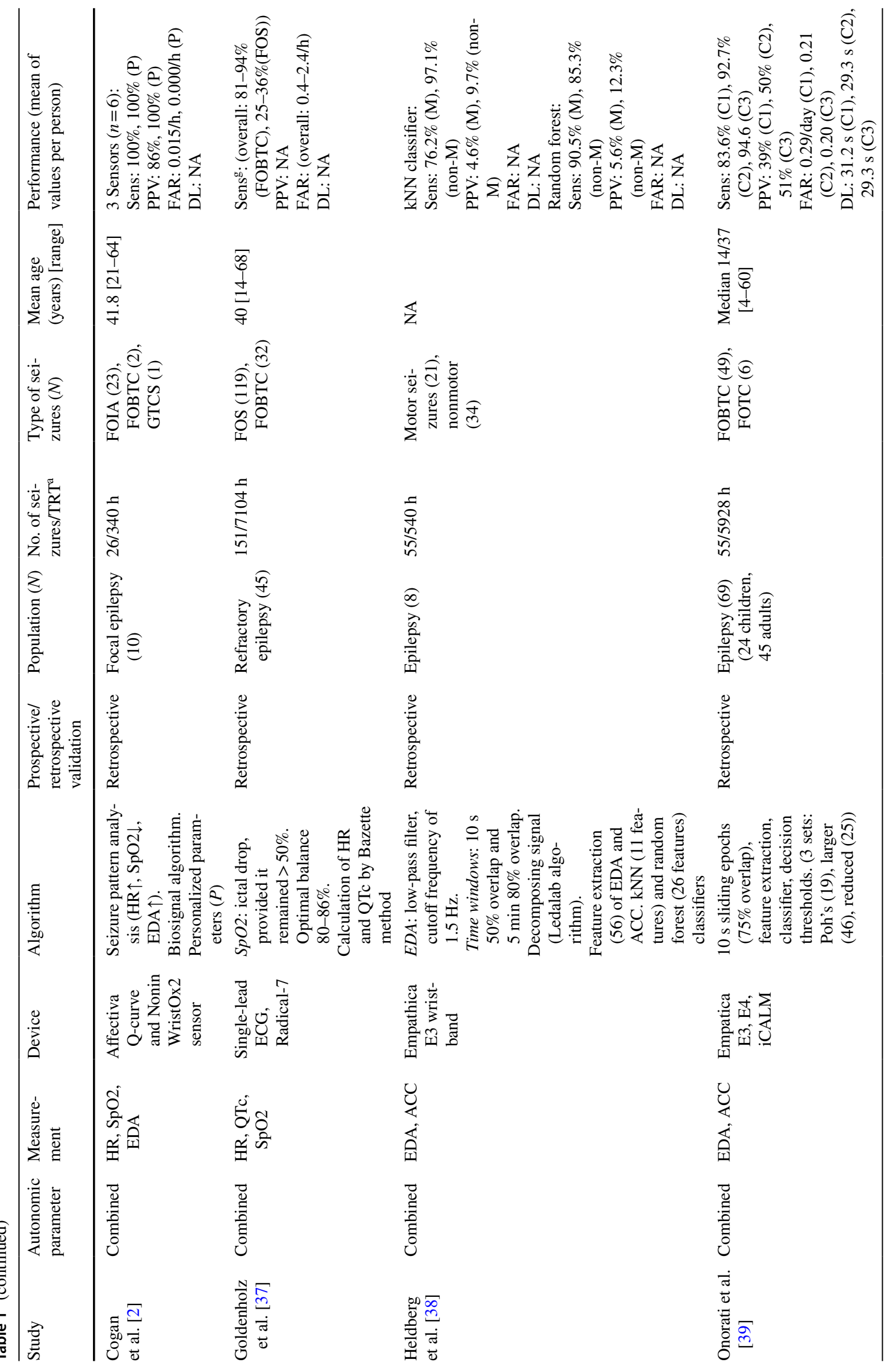




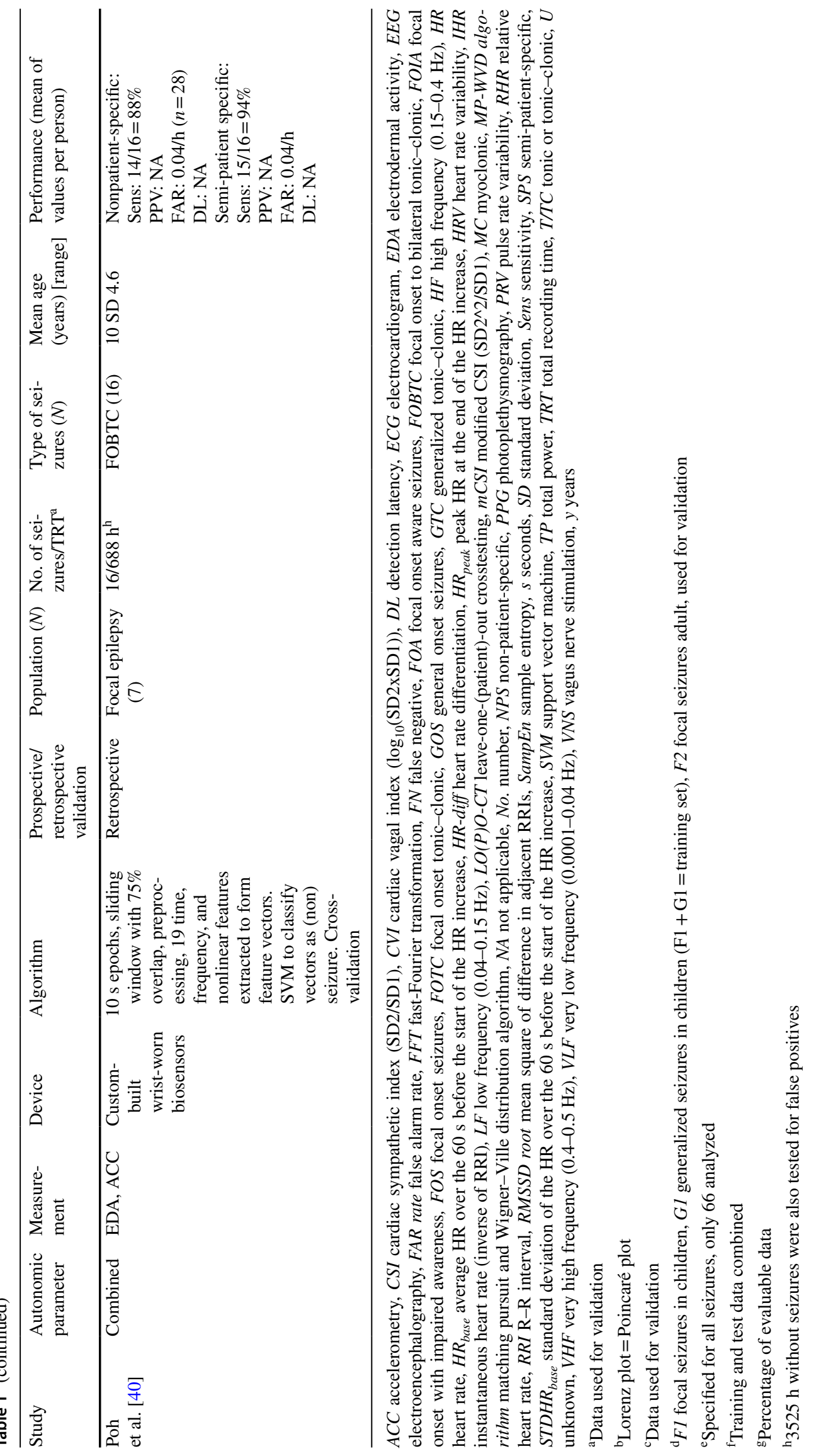


3-86 h), but was not specified in two studies. Seizure onset was mostly focal $(n=14)[8,22,24-26,28,30,31,33,34$, $37,39,40,42]$, but was focal and generalized in some $(n=4)$ $[2,23,35,42]$ or not specified in others $(n=3)[32,36,38]$.

All four performance measures (sensitivity, PPV, FAR, and DL) were only reported in three out of 21 studies [22, $33,39]$; eight studies reported three [2, 23-25, 28, 30, 31, 42], eight studies reported two [8, 26, 34, 36-38, 40, 43], one study reported one [41], and one study only reported sensitivity and PPV data for some of the subjects [32].

\section{Heart rate analysis}

Heart rate was monitored using single or multiple lead electrocardiography (ECG) in 14 of 18 studies [8, 22-26, 28, 32, 34-37, 42, 43]. Alternative methods included photoplethysmography (PPG) in a wearable sensor $(n=2)[2,30]$ and an implanted heart rate sensor (AspireSR) $(n=2)[31,33]$.

Heart rate measurement was done using various methods of R-peak detection, including those proposed by Pan and Tompkins [30, 41], Kohler [28], Yeh and Wang [22-24], or unspecified methods [8, 25, 26, 31-34, 42]. Some studies applied noise filtering techniques to diminish false R-peak detection, including high- and low-pass noise filters [8, 22-24, 26, 30] or a specific algorithm (baseline estimation and denoising with sparsity) [42].

One case study prospectively assessed a HR algorithm using a vagal nerve stimulation (VNS) device with a fixed HR sensitivity threshold [33]. Alarms were generated when the HR augmentation exceeded $50 \%$ of the baseline HR. Eleven out of 12 seizures were detected (sensitivity $92 \%$ ), together with 128 false alarms (FAR 1.88/h; $68 \mathrm{~h}$ recordings). A second prospective validation study of the same VNS device compared different HR thresholds ( $\geq 20 \%, \geq 40 \%$, and $\geq 60 \%$ increases from baseline) in 16 adults with refractory epilepsy [31]. Lower thresholds resulted in higher sensitivity and higher FAR than higher thresholds (e.g., sensitivity $59.3 \%$ and FAR $7.2 / \mathrm{h}$ for threshold $\geq 20 \%$ vs. sensitivity $18.8 \%$ and FAR $0.5 / \mathrm{h}$ for thresholds $\geq 60 \%$ ).

Similar effects of varying the thresholds (for both the relative HR increase and the duration of HR increase) were reported in two studies on retrospectively validated HR algorithms $[32,34]$. A follow-up using the same dataset examined different factors that may influence the probability of seizure detection [44]. The best regression model was created with variables including age, gender, etiology, seizure class, and years with epilepsy.

\section{Heart rate variability (HRV)}

All of the HRV-focused studies performed retrospective validations [8, 22-26, 28, 30, 41, 42]. Different HRV features were selected and specific feature thresholds were classified as 'ictal' or 'interictal.' Nine out of ten HRV studies applied linear analysis [8, 22-25, 28, 30, 41, 42] using time domain $[22-25,28,30,41,42]$ and frequency domain $[8,25,28,41$, $42]$ features. Time domain analysis focuses on the instantaneous HR; the interval between two normal QRS complexes, abbreviated to 'NN.' Different time domain features, such as the mean NN interval or the distribution of NN have been used for seizure detection. Four studies extracted and classified these time domain features using a support vector machine (SVM) classifier and validated the same HRV algorithm in different populations [22-24, 30]. The first retrospective study of 17 people with temporal lobe epilepsy found a mean sensitivity of $83.2 \%$ with a FAR of $2.01 / \mathrm{h}$ [22]. The second study extracted ECG or PPG data from three different heart rate sensors worn by 11 adults with temporal lobe epilepsy [30]. The best performance was obtained using a wearable ECG device, with a sensitivity of $64 \%$ and a FAR of $2.35 / \mathrm{h}$. A third study tested the algorithm in 28 children and showed a higher overall sensitivity (81.3\%) and a lower FAR $(0.75 / h)$ [23]. Performance, particularly FAR, improved when applying a patient-specific heuristic classifier. The latter was confirmed in the fourth study of data from 19 people with temporal lobe epilepsy from a pre-existing epilepsy database [24]. The authors also proposed an adaptive seizure detection algorithm, and showed that similar results were obtained with simulated 'real-time' user feedback.

Frequency domain analysis is used to extract the frequency components of the HR signal, each with its own physiological footprint: low frequency (LF $0.04-0.15 \mathrm{~Hz}$ ), high frequency (HF $0.15-0.40 \mathrm{~Hz}$ ), very low frequency (VLF 0.0001-0.04 Hz), and very high frequency (VHF $0.4-0.5 \mathrm{~Hz}$ ). Different frequencies were identified by power spectral density analysis of HRV in four studies [8, 25, 28, 41], and two studies sped up this process by applying an efficiency algorithm [fast Fourier transform (FFT)] [8, 28]. The LF/HF ratio, reflecting the balance of sympathetic and parasympathetic function, was examined in two studies [25, 41]. One of these studies tested a seizure detection algorithm combining both time and frequency domain features on 11 focal seizures upon awakening [25]. Ten of the 11 seizures were detected prior to seizure onset (sensitivity $91 \%$, DL $-494 \pm 262 \mathrm{~s}$ ). Another study of seven adults with focal epilepsy that used time-frequency analysis of HRV based on a combination of the matching-pursuit and Wigner-Ville distribution algorithms reported a sensitivity of $96.4 \%$ with high FAR (5.4/h) [42]. Combining ECG and EEG algorithms yielded better performance (sensitivity 100\%, FAR 1.6/h).

To assess the dynamic properties of ictal HR changes, nonlinear analysis can be applied, such as a Lorenz (or Poincaré) plot. This method plots the current R-R interval against the next $R-R$ value. Standard deviations in the transverse (SD1) and longitudinal (SD2) directions of these 
plots can be calculated, and higher ratios of SD2/SD1 reflect increased sympathetic tone. These ratios can be used in seizure detection algorithms, since an increase in sympathetic tone is often seen during the preictal and early ictal phases. One small retrospective study proposed the modified cardio sympathetic index (mCSI) as a new measure in seizure detection that reflects the sympathetic tone [26]. A seizure detection algorithm based on changes in mCSI yielded a sensitivity of $88 \%$ in five people with temporal lobe epilepsy (FAR not reported). A larger follow-up study of adults with focal epilepsy compared frequency domain analysis with Lorenz plot analysis [8]. mCSI appeared more sensitive, but FARs were not reported.

The two remaining studies of HRV combined linear and nonlinear analysis $[28,41]$. The first retrospective study of seven people with focal epilepsy reported an overall sensitivity of $88.3 \%$ with a specificity of $86.2 \%$ after selecting an optimal performance threshold for each patient [41]. The second study combined time-frequency and Lorenz plot analysis with a second nonlinear analysis of 'sample entropy' [28]. This parameter quantifies the regularity and complexity of a time series, and entropy decreases can be seen during the ictal phase. Applying all of these methods together to ECG data from twelve temporal lobe epilepsy patients resulted in overall sensitivity of $94.1 \%$ with a FAR of $0.49 / \mathrm{h}$.

Another retrospective study reported two different seizure detection algorithms based on changes in QRS morphology (algorithm 1) and cardiorespiratory interactions (algorithm 2) [35]. The first algorithm captured five consecutive QRS complexes, aligned them with respect to the $\mathrm{R}$ peak, and assembled them into one QRS matrix. Principal component analysis was used to select different features from this QRS matrix. This process was repeated for every heart beat, which resulted in a sensitivity of $89.5-100 \%$ for detecting focal onset seizures and $86 \%$ for generalized onset seizures. The second algorithm was based on the well-known modulatory effects of respiration on HRV. These cardiorespiratory changes were quantified using phase-rectified signal averaging - a methodology used to detect quasi-periodicities in nonstationary signals such as the resampled RR interval time series-and were used for seizure detection. Slightly better performance was achieved by the second algorithm, which yielded a sensitivity of $100 \%$ for focal onset seizures and $90 \%$ for generalized onset seizures. In this study, 10.4-90\% of the generated alarms were false, and this percentage was lower for the second algorithm.

\section{Combining autonomic parameters}

All multimodal autonomic algorithms were retrospectively validated. A combination of three biosignals, measured by two different devices, was used for seizure detection in a study of ten subjects with focal epilepsy [2]. An algorithm based on a specific seizure pattern of increased HR, decreased $\mathrm{SpO} 2$, and increased EDA was able to detect all seizures in six out of ten patients with a low FAR of $0.015 / \mathrm{h}$. Specific thresholds of $\mathrm{HR}, \mathrm{QTC}$, and $\mathrm{SpO} 2$ were combined in an algorithm tested on a larger study population of 45 people with refractory epilepsy [37]. Only half of the collected data was used for analysis, and a sensitivity of $81-94 \%$ was found for focal to bilateral tonic-clonic seizures, while focal seizures without bilateral spreading showed worse performance, with a sensitivity of $25-36 \%$. Overall FAR ranged from $0.4-2.4 / \mathrm{h}$.

Three other retrospective validation studies combined EDA and accelerometry (ACC), measured with one device [28-40]. Different classifiers were used to select features of EDA and ACC. The first study tested two machine learning algorithms, the k-nearest neighbor $(\mathrm{kNN})$ and random forest classifiers. The kNN classifier achieved the best results with 11 features, and was most sensitive for nonmotor seizures (sensitivity 97.1\%, FAR not reported). The random forest classifier selected 26 features and showed its best performance with motor seizures (sensitivity 90.5\%, FAR not reported). A second study used a SVM classifier to extract 19 features (16 ACC and 3 EDA) [40]. Fourteen out of 16 focal onset seizures with bilateral spreading were detected (sensitivity $88 \%$ ) and FAR was $0.04 / \mathrm{h}$. The same feature set was used in the third study and compared to a larger (40 ACC and 6 EDA) and a reduced (22 ACC and 3 EDA) feature set [39]. Retrospectively tested on 24 children and 45 adults with focal epilepsy, the reduced set showed the best performance (sensitivity $94.6 \%$, FAR 0.20 / day).

A multicenter study combined HR and ACC measures in 95 people with nocturnal major motor seizures [36]. Data from only 23 patients could be used to retrospectively validate three different algorithms based on changes in HR, ACC, and 'HR or ACC.' Clinically urgent seizures were detected well (sensitivity 71-87\%), but FAR was relatively high (2.3-6.3/night), with wide variation between subjects.

\section{Quality of the included studies}

According to the QUADAS-2 criteria, the overall quality of the included studies was medium-high (Table 2). Seventeen out of 21 studies were at risk of bias, mainly due to an undefined patient selection process and fitting of the algorithm [2, 8, 22-26, 30, 32, 34, 37-43]. There was concern regarding the applicability of the selected patients in three studies, because the populations consisted of children only and/or were not well described [23, 25, 33]. Concerns about the applicability of the index test (i.e., the tested algorithm) arose in nine studies, mainly because the algorithm was fitted to one dataset $[2,8,23,25,28,30,32,36,37]$. 
Table 2 Quality of the included studies according to QUADAS-2

\begin{tabular}{|c|c|c|c|c|c|c|c|}
\hline \multirow[t]{2}{*}{ Study } & \multicolumn{4}{|c|}{ Risk of Bias } & \multicolumn{3}{|c|}{ Concerns regarding applicability } \\
\hline & $\begin{array}{l}\text { Patient } \\
\text { selection }\end{array}$ & $\begin{array}{c}\text { Index } \\
\text { tests }\end{array}$ & $\begin{array}{l}\text { Reference } \\
\text { standard }\end{array}$ & $\begin{array}{c}\text { Flow and } \\
\text { timing }\end{array}$ & $\begin{array}{c}\text { Patient } \\
\text { selection }\end{array}$ & $\begin{array}{l}\text { Index } \\
\text { tests }\end{array}$ & $\begin{array}{l}\text { Reference } \\
\text { standard }\end{array}$ \\
\hline $\begin{array}{l}\text { Van Andel } \\
\text { et al. ' } 17^{36}\end{array}$ & - & $\bullet$ & ○ & $\bullet$ & O & - & $\bullet$ \\
\hline $\begin{array}{r}\text { Boon } \\
\text { et al. ' } 15^{31}\end{array}$ & - & - & • & • & $\bullet$ & - & - \\
\hline $\begin{array}{r}\text { Cogan } \\
\text { et al. ' } 16 a^{2}\end{array}$ & $\bullet$ & $\bullet$ & $\bullet$ & - & - & - & - \\
\hline $\begin{array}{l}\text { De Cooman } \\
\text { et al. ' } 17^{22}\end{array}$ & ○ & - & ○ & - & - & - & - \\
\hline $\begin{array}{l}\text { De Cooman } \\
\text { et al. ' } 18 a^{23}\end{array}$ & ○ & - & ○ & ○ & ○ & - & ○ \\
\hline $\begin{array}{l}\text { De Cooman } \\
\text { et al. ' } 18 b^{24}\end{array}$ & ? & $\bullet$ & ○ & $\bullet$ & - & - & $\bullet$ \\
\hline $\begin{array}{l}\text { Elmpt, van } \\
\text { et al. ' } 06^{32}\end{array}$ & - & $\bullet$ & ○ & O & - & - & ? \\
\hline $\begin{array}{l}\text { Fujiwara } \\
\text { et al. ' } 16^{25}\end{array}$ & - & • & • & $\bullet$ & $\bullet$ & $\bullet$ & $\bullet$ \\
\hline $\begin{array}{l}\text { Goldenholz } \\
\text { et al. ' } 17^{37}\end{array}$ & - & - & • & - & - & - & $\bullet$ \\
\hline $\begin{array}{r}\text { Hampel } \\
\text { et al. ' } 15^{33}\end{array}$ & 0 & 0 & 0 & $\bullet$ & $\bullet$ & 0 & 0 \\
\hline $\begin{array}{l}\text { Heldberg } \\
\text { et al. ' } 15^{38}\end{array}$ & 0 & 0 & 0 & 0 & 0 & 0 & 0 \\
\hline $\begin{array}{l}\text { Jeppesen } \\
\text { et al. ' } 14^{26}\end{array}$ & 0 & 0 & • & $\bullet$ & 0 & ○ & 0 \\
\hline $\begin{array}{l}\text { Jeppesen } \\
\text { et al. ' } 15^{8}\end{array}$ & ○ & $\bullet$ & ○ & $\bullet$ & $\bullet$ & $\bullet$ & $\bullet$ \\
\hline $\begin{array}{l}\text { Moridani } \\
\text { et al. ' } 17^{27}\end{array}$ & $\bullet$ & 0 & 0 & $\bullet$ & 0 & ○ & $\bullet$ \\
\hline $\begin{array}{r}\text { Onorati } \\
\text { et al. ' } 17^{39}\end{array}$ & $\bullet$ & • & • & $\bullet$ & ○ & 0 & ○ \\
\hline $\begin{array}{r}\text { Osorio } \\
\text { et al. ' } 14^{34}\end{array}$ & $\bullet$ & - & 0 & ○ & 0 & - & 0 \\
\hline $\begin{array}{r}\text { Pavei } \\
\text { et al. ' } 17^{28}\end{array}$ & ○ & $\bullet$ & 0 & $\bullet$ & 0 & 0 & 0 \\
\hline $\begin{array}{r}\text { Poh } \\
\text { et al. ' } 12^{40}\end{array}$ & 0 & 0 & • & 0 & 0 & 0 & 0 \\
\hline $\begin{array}{r}\text { Qaraqe } \\
\text { et al. ' } 16^{29}\end{array}$ & • & 0 & 0 & 0 & ○ & 0 & 0 \\
\hline $\begin{array}{r}\text { Vandecasteele } \\
\text { et al. }{ }^{\prime} 17^{30}\end{array}$ & $\bullet$ & • & ○ & 0 & 0 & - & ○ \\
\hline $\begin{array}{l}\text { Varon } \\
\text { et al. ' } 15^{43}\end{array}$ & $\bullet$ & - & 0 & • & ○ & - & - \\
\hline
\end{tabular}




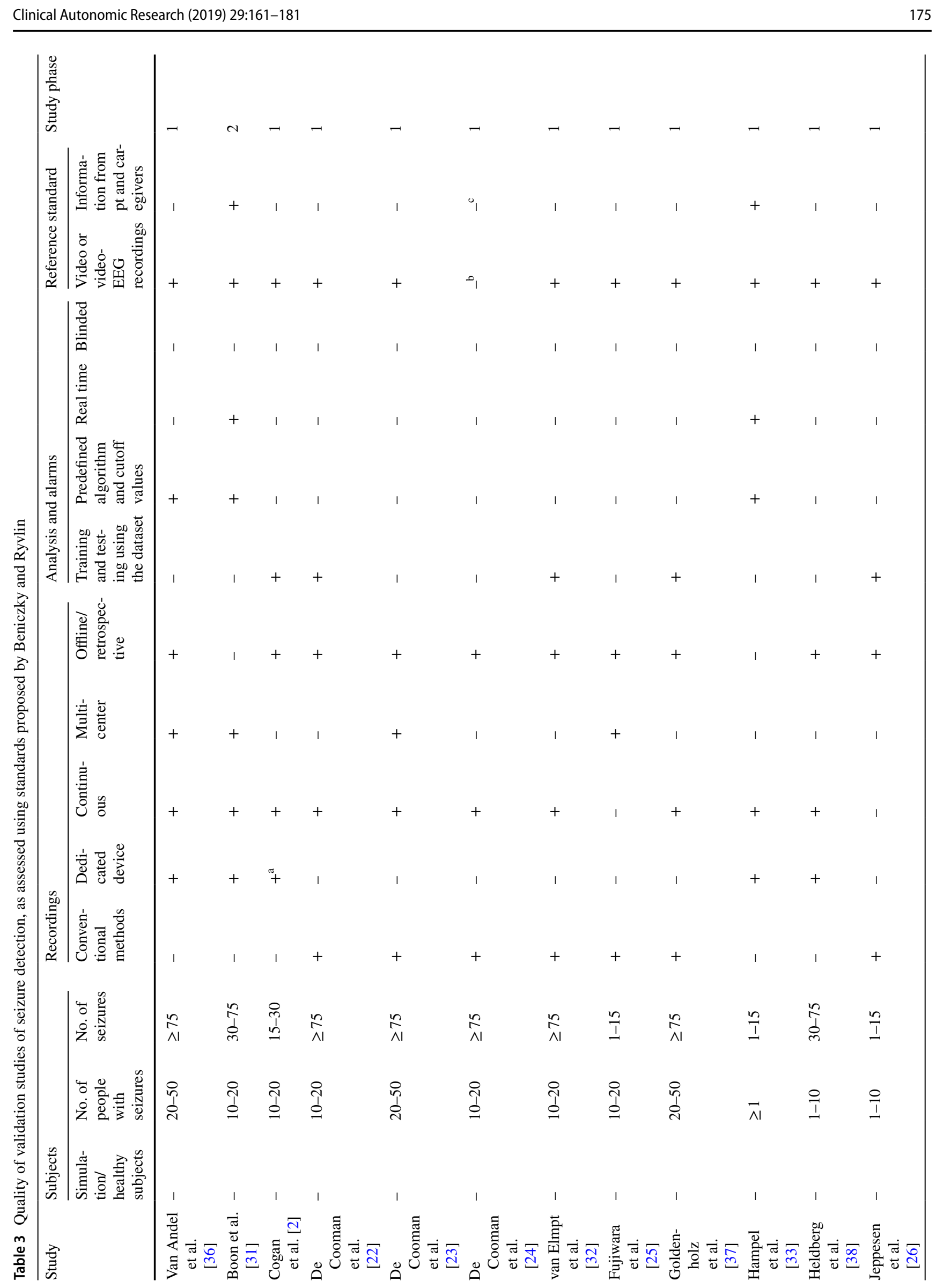

Springer 


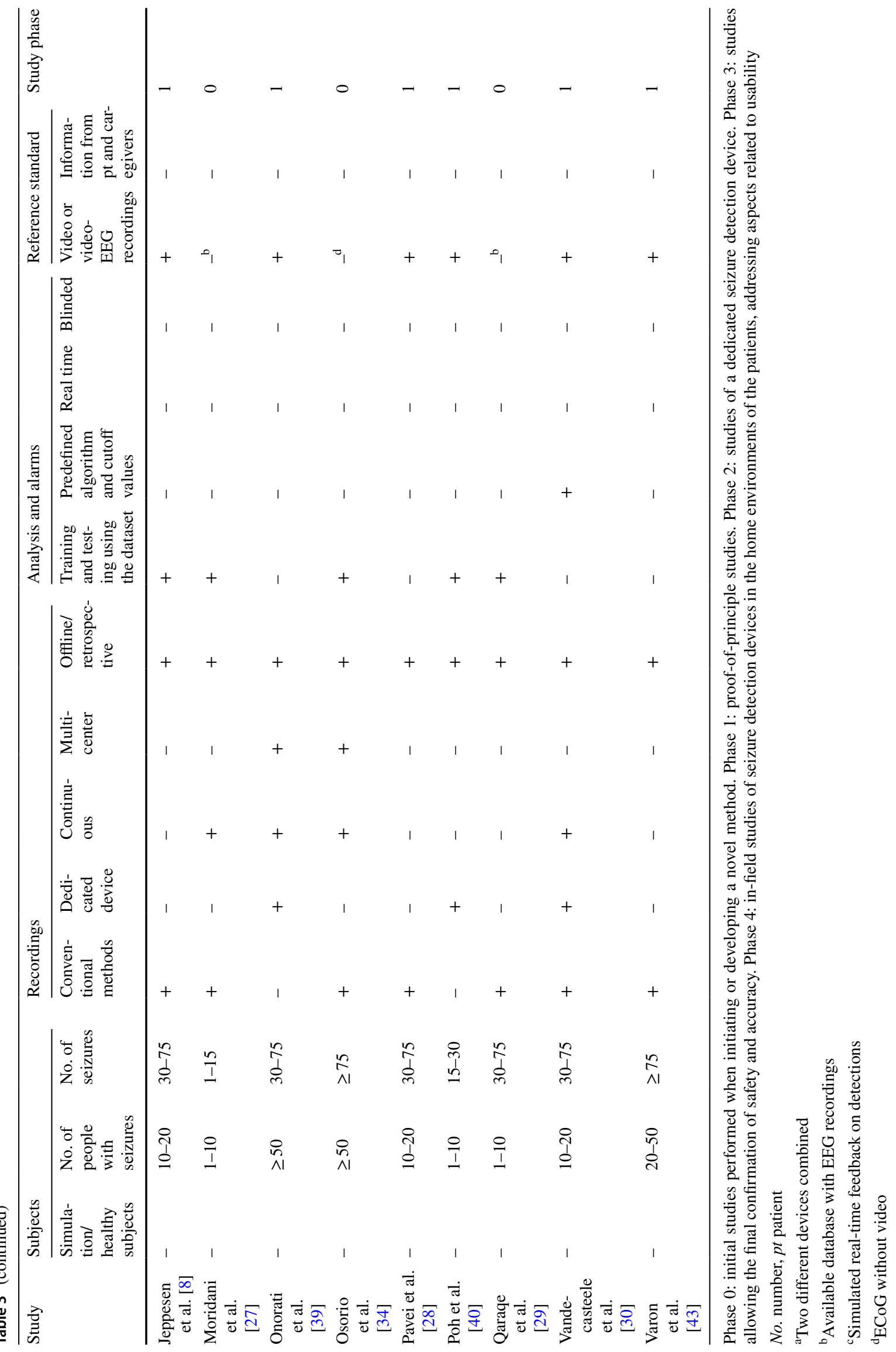


Table 4 Performance of seizure detection algorithms grouped according to dataset size

\begin{tabular}{|c|c|c|c|c|c|c|c|c|}
\hline \multirow[t]{2}{*}{ Study } & \multicolumn{4}{|c|}{ Validation of algorithm } & \multicolumn{4}{|c|}{ Performance of algorithm } \\
\hline & $\begin{array}{l}\text { No. of } \\
\text { sub- } \\
\text { jects }\end{array}$ & $\begin{array}{l}\text { No. of sei- } \\
\text { zures/TRT }\end{array}$ & $\begin{array}{l}\text { Type of sei- } \\
\text { zures }\end{array}$ & Algorithm & Sensitivity (\%) & FAR & PPV (\%) & DL (s) [range] \\
\hline \multicolumn{9}{|l|}{ Large datasets } \\
\hline \multirow{6}{*}{$\begin{array}{l}\text { van Andel } \\
\text { et al. [36] }\end{array}$} & \multirow[t]{6}{*}{23} & \multirow[t]{3}{*}{$86 / 402 \mathrm{~h}^{\mathrm{a}}$} & \multirow{3}{*}{$\begin{array}{l}\text { All major } \\
\text { motorb }^{b}\end{array}$} & Heart rate & 60 & $0.5 / \mathrm{h}$ & NA & NA \\
\hline & & & & Movement & 56 & $0.3 / \mathrm{h}$ & NA & NA \\
\hline & & & & $\begin{array}{l}\text { Hart rate or } \\
\text { movement }\end{array}$ & 71 & $0.7 / \mathrm{h}$ & NA & NA \\
\hline & & \multirow[t]{3}{*}{59} & \multirow{3}{*}{$\begin{array}{l}\text { Clinically } \\
\text { urgent } \\
\text { seizures }^{c}\end{array}$} & Heart rate & 74 & $0.6 / \mathrm{h}$ & NA & NA \\
\hline & & & & Movement & 71 & $0.3 / \mathrm{h}$ & NA & NA \\
\hline & & & & $\begin{array}{l}\text { Hart rate or } \\
\text { movement }\end{array}$ & 87 & $0.8 / \mathrm{h}$ & NA & NA \\
\hline $\begin{array}{l}\text { De Cooman } \\
\text { et al. [22] }\end{array}$ & 17 & $127 / 918 \mathrm{~h}$ & $\begin{array}{l}\text { FOS, including } \\
\text { TCs }\end{array}$ & & $83.2[50-100]$ & $\begin{array}{l}2.01 / \mathrm{h}[0.88- \\
3.52 / \mathrm{h}]\end{array}$ & $\begin{array}{l}7.9 \% \\
{[0.4-21 \%]}\end{array}$ & $\begin{array}{l}13.3[-18.2- \\
54.3]\end{array}$ \\
\hline \multirow[t]{2}{*}{$\begin{array}{l}\text { De Cooman } \\
\text { et al. [23] }\end{array}$} & \multirow[t]{2}{*}{28} & \multirow[t]{2}{*}{$107 / 695 \mathrm{~h}$} & \multirow{2}{*}{$\begin{array}{l}\text { Convulsive } \\
\text { and clini- } \\
\text { cal subtle } \\
\text { seizures }\end{array}$} & $\begin{array}{l}\text { Patient-inde- } \\
\text { pendent }\end{array}$ & Overall: 81.3 & Overall: $0.75 / \mathrm{h}$ & NA & NA \\
\hline & & & & $\begin{array}{l}\text { Patient-spe- } \\
\text { cific }\end{array}$ & Overall: 77.6 & Overall: $0.33 / \mathrm{h}$ & Overall: 30.7 & 19.1 \\
\hline \multirow[t]{3}{*}{$\begin{array}{l}\text { De Cooman } \\
\text { et al. [24] }\end{array}$} & \multirow[t]{3}{*}{19} & \multirow[t]{3}{*}{$153 / 2833 \mathrm{~h}$} & \multirow{3}{*}{$\begin{array}{l}\text { FOS, includ- } \\
\text { ing TCs } \\
\text { (only clinical } \\
\text { seizures) }\end{array}$} & $\begin{array}{l}\text { Patient-inde- } \\
\text { pendent }\end{array}$ & Overall: 78.4 & Overall: $1.73 / \mathrm{h}$ & Overall: 2.4 & NA \\
\hline & & & & $\begin{array}{l}\text { Patient-spe- } \\
\text { cific }\end{array}$ & Overall: 76.5 & Overall: $1.09 / \mathrm{h}$ & Overall: 3.7 & NA \\
\hline & & & & Adaptive & Overall: 77.1 & Overall: $1.24 / \mathrm{h}$ & Overall: 3.3 & NA \\
\hline $\begin{array}{r}\text { Goldenholz } \\
\text { et al. [37] }\end{array}$ & 45 & $151 / 7104 \mathrm{~h}$ & $\begin{array}{l}\text { FOS, including } \\
\text { TCs }\end{array}$ & & $\begin{array}{l}\text { Overall: 81-94 } \\
\text { (FOBTC) } \\
25-36 \\
(\text { FOS })^{\mathrm{e}}\end{array}$ & $\begin{array}{l}\text { Overall: } \\
0.4-2.4 / \mathrm{h}\end{array}$ & NA & NA \\
\hline \multirow{3}{*}{$\begin{array}{l}\text { Onorati et al. } \\
\text { [39] }\end{array}$} & \multirow[t]{3}{*}{69} & \multirow[t]{3}{*}{$55 / 5928 \mathrm{~h}$} & \multirow[t]{3}{*}{ FOS, all TCs } & Classifier 1 & 83.6 & $0.29 /$ day & 39 & 31.2 \\
\hline & & & & Classifier 2 & 92.7 & $0.21 /$ day & 50 & 29.3 \\
\hline & & & & Classifier 3 & 94.6 & $0.20 /$ day & 51 & 29.3 \\
\hline \multicolumn{9}{|c|}{ Medium datasets } \\
\hline \multirow[t]{3}{*}{$\begin{array}{l}\text { Boon et al. } \\
\text { [31] }\end{array}$} & \multirow[t]{3}{*}{16} & \multirow[t]{3}{*}{ 66/NA } & \multirow{3}{*}{$\begin{array}{l}\text { Different types } \\
\text { of FOS, } \\
\text { including } \\
\text { TCs }\end{array}$} & $\begin{array}{l}\text { Thresh- } \\
\text { old }>20 \%\end{array}$ & 59.3 & $\begin{array}{c}7.2 / \mathrm{h}[95 \% \text { CI } \\
5.31-9.94]\end{array}$ & NA & $6.0[-112-105]$ \\
\hline & & & & $\begin{array}{l}\text { Thresh- } \\
\text { old }>40 \%\end{array}$ & 34.8 & $\begin{array}{c}2.7 / \mathrm{h}[95 \% \mathrm{CI} \\
1.70-3.91]\end{array}$ & NA & $27.5[0-57]$ \\
\hline & & & & $\begin{array}{l}\text { Thresh- } \\
\text { old }>60 \%\end{array}$ & 18.8 & $\begin{array}{c}0.5 / \mathrm{h}[95 \% \mathrm{CI} \\
0.20-0.96]\end{array}$ & NA & $35.0[4-40]$ \\
\hline \multirow[t]{2}{*}{$\begin{array}{l}\text { Heldberg et al. } \\
\text { [38] }\end{array}$} & \multirow[t]{2}{*}{8} & \multirow[t]{2}{*}{$55 / 540 \mathrm{~h}$} & $\begin{array}{l}\text { Motor (M) } \\
\text { and non-M }\end{array}$ & $\mathrm{kNN}$ classifier & $\begin{array}{l}76.2(\mathrm{M}) \\
97.1 \text { (non-M) }\end{array}$ & NA & $\begin{array}{l}4.6(\mathrm{M}) \\
9.7(\text { non-M) }\end{array}$ & NA \\
\hline & & & & Random forest & $\begin{array}{l}90.5(\mathrm{M}) \\
85.3(\text { non-M) }\end{array}$ & NA & $\begin{array}{l}5.6(\mathrm{M}) \\
12.3(\text { non-M) }\end{array}$ & NA \\
\hline $\begin{array}{l}\text { Jeppesen et al. } \\
\text { [8] }\end{array}$ & 17 & $47 / \pm 27 \mathrm{~h}$ & $\begin{array}{l}\text { FOS, including } \\
\text { TCs }\end{array}$ & & $\begin{array}{l}\text { 81: (mCSI- } \\
\text { 100) } \\
\text { (overall: 74, } \\
\text { mCSI-100) }\end{array}$ & NA & NA & $16[6-50]$ \\
\hline $\begin{array}{l}\text { Osorio et al. } \\
{[34]}\end{array}$ & 81 & $241 / 6935 \mathrm{~h}$ & FOS & $\begin{array}{l}\text { Lowest set- } \\
\text { tings T,D } \\
\text { Datasets (1) } \\
\text { and (2) }\end{array}$ & 98.8 & $\begin{array}{l}9.5 / \mathrm{h}(1) \\
7.2 / \mathrm{h}(2)\end{array}$ & NA & NA \\
\hline & & & & $\begin{array}{l}\text { Highest set- } \\
\text { tings T,D } \\
\text { Datasets (1) } \\
\text { and (2) }\end{array}$ & 85.5 & $\begin{array}{l}1.1 / \mathrm{h}(1) \\
0.7 / \mathrm{h}(2)\end{array}$ & NA & NA \\
\hline $\begin{array}{l}\text { Pavei et al. } \\
\text { [28] }\end{array}$ & 12 & $34 / 171 \mathrm{~h}$ & FOIA & & Overall: 94.1 & Overall: $0.49 / \mathrm{h}$ & Overall: 95.6 & NA \\
\hline
\end{tabular}


Table 4 (continued)

\begin{tabular}{|c|c|c|c|c|c|c|c|c|}
\hline \multirow[t]{2}{*}{ Study } & \multicolumn{4}{|c|}{ Validation of algorithm } & \multicolumn{4}{|c|}{ Performance of algorithm } \\
\hline & $\begin{array}{l}\text { No. of } \\
\text { sub- } \\
\text { jects }\end{array}$ & $\begin{array}{l}\text { No. of sei- } \\
\text { zures/TRT }\end{array}$ & $\begin{array}{l}\text { Type of sei- } \\
\text { zures }\end{array}$ & Algorithm & Sensitivity (\%) & FAR & PPV (\%) & DL (s) [range] \\
\hline \multirow[t]{2}{*}{ Poh et al. [40] } & \multirow[t]{2}{*}{7} & \multirow[t]{2}{*}{$16 / 688 \mathrm{~h}^{\mathrm{f}}$} & \multirow[t]{2}{*}{ FOS, all TCs } & $\begin{array}{l}\text { Non-patient- } \\
\text { specific }\end{array}$ & 88 & $0.04 / \mathrm{h}(n=28)$ & NA & NA \\
\hline & & & & $\begin{array}{l}\text { Semi-patient- } \\
\text { specific }\end{array}$ & 94 & $0.04 / \mathrm{h}$ & NA & NA \\
\hline \multirow{2}{*}{$\begin{array}{l}\text { Qaraqe et al. } \\
\text { [29] }\end{array}$} & \multirow[t]{2}{*}{7} & \multirow[t]{2}{*}{ 68/NA } & \multirow{2}{*}{$\begin{array}{l}\text { FOS, including } \\
\text { TCs }\end{array}$} & ECG & $96.4[75-100]$ & $5.4 / \mathrm{h}[1.5-9.5 / \mathrm{h}]$ & NA & $13.1[8-20.5]$ \\
\hline & & & & $\mathrm{ECG}+\mathrm{EEG}$ & 100 & $1.6 / \mathrm{h}[0-3.5 / \mathrm{h}]$ & NA & $12.3[3-26]$ \\
\hline \multirow[t]{3}{*}{$\begin{array}{l}\text { Vandecasteele } \\
\text { et al. [30] }\end{array}$} & \multirow[t]{3}{*}{11} & \multirow[t]{3}{*}{$47 / 701 \mathrm{~h}$} & \multirow[t]{3}{*}{ FOIA } & Wearable ECG & $\begin{array}{l}64 \text { (overall: } \\
70)\end{array}$ & $\begin{array}{l}2.35 / \mathrm{h} \text { (overall: } \\
2.11 / \mathrm{h} \text { ) }\end{array}$ & $\begin{array}{l}2.03 \text { (overall: } \\
2.15)\end{array}$ & NA \\
\hline & & & & Hospital ECG & $\begin{array}{l}57 \text { (overall: } \\
57 \text { ) }\end{array}$ & $\begin{array}{l}2.05 / \mathrm{h} \text { (overall: } \\
1.92 / \mathrm{h} \text { ) }\end{array}$ & $\begin{array}{l}2.22 \text { (overall: } \\
1.93 \text { ) }\end{array}$ & NA \\
\hline & & & & PPG & 33 (overall:32) & $\begin{array}{l}1.88 / \mathrm{h} \\
\quad \text { (overall:1.80/h) }\end{array}$ & $\begin{array}{l}1.43 \text { (overall: } \\
1.12 \text { ) }\end{array}$ & NA \\
\hline \multicolumn{9}{|l|}{ Small datasets } \\
\hline \multirow{2}{*}{$\begin{array}{l}\text { Cogan et al. } \\
\text { [2] }\end{array}$} & \multirow[t]{2}{*}{6} & \multirow[t]{2}{*}{$10 / 340 \mathrm{~h}$} & \multirow[t]{2}{*}{ FOIA and TCs } & 3 Sensors & 100 & $0.015 / \mathrm{h}$ & 86 & NA \\
\hline & & & & Personalized & 100 & $0.000 / \mathrm{h}$ & 100 & NA \\
\hline $\begin{array}{l}\text { Elmpt, van et } \\
\text { [32] }\end{array}$ & 10 & $104 / 9 \mathrm{~h}$ & $\begin{array}{c}\text { Motor seizures } \\
\text { (T, TC, MC) } \\
\text { and atypical } \\
\text { absences }\end{array}$ & & $\mathrm{NA}^{\mathrm{d}}$ & NA & NA & NA \\
\hline \multirow{2}{*}{$\begin{array}{l}\text { Fujiwara et al. } \\
\text { [25] }\end{array}$} & \multirow[t]{2}{*}{14} & \multirow[t]{2}{*}{$11 / 69 \mathrm{~h}$} & \multirow[t]{2}{*}{ FOS (awake) } & $T^{2}$ statistics & Overall: 55 & Overall: $1.2 / \mathrm{h}$ & NA & $-524 \pm 216$ \\
\hline & & & & $Q$ statistics & Overall: 91 & Overall: $0.7 / \mathrm{h}$ & NA & $-494 \pm 262$ \\
\hline $\begin{array}{l}\text { Hampel et al. } \\
\text { [33] }\end{array}$ & 1 & $12 / 68 \mathrm{~h}$ & $\begin{array}{l}\text { FOS with } \\
\text { hyperkinetic } \\
\text { movements }\end{array}$ & & 92 & $1.88 / \mathrm{h}$ & 8 & $7.4( \pm 5)$ \\
\hline $\begin{array}{l}\text { Jeppesen et al. } \\
\text { [26] }\end{array}$ & 5 & $11 / 13 \mathrm{~h}$ & FOIA & & $\begin{array}{l}88 \text { (CSI-30) } \\
\text { (overall: } \\
\text { 73, CSI-30, } \\
\text { mCSI-50) }\end{array}$ & NA & NA & $-5-60$ \\
\hline $\begin{array}{l}\text { Moridani et al. } \\
\text { [27] }\end{array}$ & 7 & $11 / \pm 6 h$ & FOS & & Overall: 88.3 & NA & NA & NA \\
\hline \multirow{6}{*}{$\begin{array}{l}\text { Varon et al. } \\
\text { [43] }\end{array}$} & \multirow[t]{6}{*}{42} & \multirow[t]{6}{*}{$108 / \pm 5 \mathrm{~h}$} & \multirow{6}{*}{$\begin{array}{l}\text { FOS and GOS, } \\
\text { including T, } \\
\text { TC, MC, and } \\
\text { absences }\end{array}$} & Algorithm $1^{\mathrm{g}}$ & $89.5(\mathrm{~F} 1)$ & NA & 85.7 (F1) & NA \\
\hline & & & & & 86 (G1) & & $57.3(\mathrm{G} 1)$ & \\
\hline & & & & & $100(\mathrm{~F} 2)$ & & $52.6(\mathrm{~F} 2)$ & \\
\hline & & & & Algorithm $2^{\mathrm{f}}$ & $100(\mathrm{~F} 1)$ & NA & $90.5(\mathrm{~F} 1)$ & NA \\
\hline & & & & & $90(\mathrm{G} 1)$ & & 77.5 (G1) & \\
\hline & & & & & $100(\mathrm{~F} 2)$ & & $71.4(\mathrm{~F} 2)$ & \\
\hline
\end{tabular}

CSI cardiac sympathetic index, DL detection latency, ECG electrocardiogram, EEG electroencephalography, FAR rate false alarm rate, FOBTC focal onset to bilateral tonic-clonic, FOIA focal onset with impaired awareness, FOS focal onset seizures, $h$ hour, $M C$ myoclonic, $m C S I$ modified cardiac sympathetic index, NA not applicable, No. number, $P P G$ photoplethysmography, $s$ seconds, $T$ tonic, $T C s$ tonic-clonic seizures, $T R T$ total recording time

${ }^{\text {a }}$ Training and test set combined

${ }^{\mathrm{b}}$ Including tonic-clonic, tonic, hypermotor, and cluster (series of at least five tonic or myoclonic spasms within 3 min)

${ }^{\mathrm{c}}$ When attendance or intervention was deemed necessary, based on seizure severity, postictal arousal state, breathing difficulties, and distress

${ }^{\mathrm{d}}$ High variability in sensitivity and PPV

${ }^{\text {e}}$ Percentage of evaluable data

${ }^{\mathrm{f}} 3525 \mathrm{~h}$ without seizures were also tested for false positives

${ }^{\mathrm{g}} \mathrm{F} 1$ focal seizures in children, $G 1$ generalized seizures in children $(\mathrm{F} 1+\mathrm{G} 1=$ training set $), F 2$ focal seizures in adults, used for validation 
Based on the standards for the clinical validation of SDDs proposed by Beniczky and Ryvlin [21], most studies were classified as phase 1 proof-of-principle studies, whereas three were classified as phase 0 initial studies [34, 41, 42], and only one as a phase 2 study on a dedicated SDD [31] (Table 3). Seven other studies also tested a dedicated device but included small population sizes or did not address the safety of the device and were therefore classified as phase 1 $[2,30,33,36,38-40]$. Ten studies trained and tested their algorithm on the same dataset $[2,8,22,26,32,34,37$, $40-42]$, and only four used a predefined algorithm or cutoff values $[30,31,33,36]$. Eighteen studies used video-EEG as reference standard; the remaining three used EEG or ECoG without video recordings $[34,41,42]$.

\section{Discussion}

The overall quality of studies on seizure detection using autonomic parameters is low. Small population sizes, short follow-up periods, and high study heterogeneity raise concerns about the applicability of the results. Available studies are mainly initial or proof-of-principle studies that lack long-term and real-time ambulatory monitoring, which is needed to obtain more reliable performance data and usability outcomes.

HR- or HRV-based algorithms are most frequently applied, but it is hard to compare the results of different studies due to wide variation in the detection techniques used and a lack of FAR data (Table 4). Additionally, FAR, when mentioned, is high for these studies and exceeds acceptable limits for daily practice. We could not compare the performance of HR- and HRV-based algorithms due to the wide variety of study designs employed. HRV-based algorithms seem attractive given their short detection latency, but they still require prospective validation. HRV is, however, situation dependent and affected by exercise, stress, respiration, and sleep stage [45-47]. These confounding factors make it more challenging to distinguish ictal patterns from nonictal ones, resulting in lower accuracy [48]. Also, similar activation of the autonomic nervous system can occur before physiological arousal or other sleep-related movements [49].

Multimodal algorithms might help to lower FARs. A retrospective study of seven children with tonic-clonic seizures validated different unimodal and multimodal algorithms on the same dataset. All combinations of multimodal sensors, including ECG, EMG, and ACC, showed at least $75 \%$ lower FAR [50]. Studies differentiating outcome according to seizure type showed diverse results, indicating that that different seizure types may require different detection techniques. Multimodal techniques can provide a solution to this problem [51]. Another solution could be personalizing or tailoring the algorithm. One study group studied two different personalization strategies and calculated the number of seizures required for accurate tailoring [52]. The authors proposed an initialization phase to tailor an existing predefined algorithm to a patient-specific algorithm. Six to eight seizures seemed sufficient to set individual thresholds [52]. Another retrospective multicenter study proposed an automatic adaptive HRV algorithm and tested it on a database of 107 nocturnal seizures from 28 children [23]. After an initialization phase of five seizures, the personalized algorithm resulted in lower FARs compared to those obtained with the patient-independent algorithm. A follow-up study proposed an adaptive classifier with real-time user feedback that presented similar performance; this method might be better accepted in daily practice [24].

\section{Conclusion}

Autonomic function alterations seem to represent an attractive tool for timely seizure detection. Unimodal autonomic algorithms cannot, however, reach acceptable performance: while most algorithms are quite sensitive, false alarm rates are still too high. Multimodal algorithms and personalization of the algorithm are important strategies to improve performance. Larger, prospective, home-based studies with long-term follow-up are needed to validate these methods and to demonstrate the added value of SDDs in clinical care.

Acknowledgements Thomas De Cooman is supported by an FWO SBO PhD grant. Sabine Van Huffel is supported by imec ICON HBC.2016.0167 project 'SeizeIT.' Roland Thijs is supported by The Netherlands Organization for Health Research and Development (ZonMW, grant number 40-41200-98-9335), the Dutch Epilepsy Fund, Christelijke Vereniging voor de verpleging van Lijders aan Epilepsie.

\section{Compliance with ethical standards}

Conflict of interest On behalf of all the authors, the corresponding author states that there is no conflict of interest. Roland Thijs has received research support from Medtronic and the AC Thomson Foundation and fees for lectures from Medtronic, UCB and GSK outside the submitted work.

Open Access This article is distributed under the terms of the Creative Commons Attribution 4.0 International License (http://creativeco mmons.org/licenses/by/4.0/), which permits unrestricted use, distribution, and reproduction in any medium, provided you give appropriate credit to the original author(s) and the source, provide a link to the Creative Commons license, and indicate if changes were made.

\section{References}

1. Van Andel J, Thijs RD, de Weerd A, Arends J, Leijten F (2016) Non-EEG based ambulatory seizure detection designed for home use: what is available and how will it influence epilepsy 
care? Epilepsy Behav 57:82-89. https://doi.org/10.1016/j.yebeh .2016.01.003

2. Cogan D, Birjandtalab J, Nourani M (2016) Multi-biosignal analysis for epileptic seizure monitoring. Int J Neural Syst 26:1-18. https://doi.org/10.1142/S0129065716500313

3. Elger CE, Hoppe C (2018) Diagnostic challenges in epilepsy: seizure under-reporting and seizure detection. Lancet Neurol 17(3):279-288. https://doi.org/10.1016/S1474-4422(18)30038-3

4. Van der Lende M, Cox FME, Visser GH, Sander JW, Thijs RD (2016) Value of video monitoring for nocturnal seizure detection in a residential setting. Epilepsia 57(11):1748-1753. https://doi. org/10.1111/epi.13558

5. Van der Lende M, Hesdorffer DC, Sander JW, Thijs RD (2018) Nocturnal supervision and SUDEP risk at different epilepsy care settings. Neurology 91(16):e1508-e1518

6. Van de Vel A, Cuppens K, Bonroy B et al (2016) Non-EEG seizure detection systems and potential SUDEP prevention: state of the art: review and update. Seizure 41:141-153. https://doi. org/10.1016/j.seizure.2016.07.012

7. Devinsky O (2004) Effects of seizures on autonomic and cardiovascular function. Epilepsy Curr 4(2):43-46. https://doi.org/10.1 111/j.1535-7597.2004.42001.x

8. Jeppesen J, Beniczky S, Johansen P, Sidenius P, Fuglsang-Frederiksen A (2015) Detection of epileptic seizures with a modified heart rate variability algorithm based on Lorenz plot. Seizure 24:1-7. https://doi.org/10.1016/j.seizure.2014.11.004

9. Sevcencu C, Struijk JJ (2010) Autonomic alterations and cardiac changes in epilepsy. Epilepsia 51(5):725-737. https://doi.org/10. $1111 / j .1528-1167.2009 .02479 . x$

10. Leutmezer F, Schernthaner C, Lurger S, Potzelberger K, Baumgartner C (2003) Electrocardiographic changes at the onset of epileptic seizures. Epilepsia 44(3):348-354

11. Blumhardt LD, Smith PEM (1986) Electrocardiographic accompaniments of temporal lobe epileptic seizures. Lancet 1(8489):1051-1055

12. Zijlmans M, Flanagan D, Gotman J (2002) Heart rate changes and ECG abnormalities during epileptic seizures: prevalence and definition of an objective clinical sign. Epilepsia 43(8):847-854

13. Bruno E, Biondi A, Richardson MP (2018) Pre-ictal heart rate changes : a systematic review and meta-analysis. Seizure 55:4856. https://doi.org/10.1016/j.seizure.2018.01.003

14. Bateman LM, Li C, Seyal M (2008) Ictal hypoxemia in localization-related epilepsy: analysis of incidence, severity and risk factors. Brain 131:3239-3245. https://doi.org/10.1093/brain/awn27 7

15. Lacuey N, Zonjy B, Hampson JP et al (2017) The incidence and significance of periictal apnea in epileptic seizures. Epilepsia 2018:1-10. https://doi.org/10.1111/epi.14006

16. Van der Lende M, Surges R, Sander JW, Thijs RD (2016) Cardiac arrhythmias during or after epileptic seizures. J Neurol Neurosurg Psychiatry 87(1):69-74. https://doi.org/10.1136/jnnp-2015-31055 9

17. Massey CA, Sowers LP, Dlouhy BJ, Richerson GB (2014) SUDEP mechanisms: the pathway to prevention. Nat Rev Neurol 10(5):271-282. https://doi.org/10.1038/nchembio.1527.A

18. Ryvlin P, Nashef L, Lhatoo SD et al (2013) Incidence and mechanisms of cardiorespiratory arrests in epilepsy monitoring units (MORTEMUS): a retrospective study. Lancet Neurol 12:966-977. https://doi.org/10.1016/S1474-4422(13)70214-X

19. Moher D, Shamseer L, Clarke M et al (2015) Preferred reporting items for systematic review and meta-analysis protocols (PRISMA-P) 2015 statement. Syst Rev 4(1):1-9. https://doi. org/10.1186/2046-4053-4-1

20. Whiting PF, Rutjes AWS, Westwood ME et al (2011) Research and reporting methods accuracy studies. Ann Intern Med 155(4):529-536
21. Beniczky S, Ryvlin P (2018) Standards for testing and clinical validation of seizure detection devices. Epilepsia 59(S1):9-13. https://doi.org/10.1111/epi.14049

22. De Cooman T, Varon C, Hunyadi B et al (2017) Online automated seizure detection in temporal lobe epilepsy patients using single-lead ECG. Int J Neural Syst 27(7):1750022. https://doi. org/10.1142/s0129065717500228

23. De Cooman T, Varon C, Van de Vel A et al (2018) Adaptive nocturnal seizure detection using heart rate and low-complexity novelty detection. Seizure 59:48-53. https://doi.org/10.1016/j. seizure.2018.04.020

24. De Cooman T, Kjaer TW, Van Huffel S, Sorensen HB (2018) Adaptive heart rate-based epileptic seizure detection using realtime user feedback. Physiol Meas 39:014005

25. Fujiwara K, Miyajima M, Yamakawa T et al (2016) Epileptic seizure prediction based on multivariate statistical process control of heart rate variability features. IEEE Trans Biomed Eng 63(6):1321-1332. https://doi.org/10.1109/TBME.2015.2512276

26. Jeppesen J, Beniczky S, Johansen P, Sidenius P, Fuglsang-Frederiksen A (2014) Using Lorenz plot and cardiac sympathetic index of heart rate variability for detecting seizures for patients with epilepsy. IEEE Eng Med Biol Soc 4563-4566

27. Moridani MK, Farhadi H (2017) Heart rate variability as a biomarker for epilepsy seizure prediction. Bratisl Lek Listy 118(1):38. https://doi.org/10.4149/BLL_2017_001

28. Pavei J, Heinzen RG, Novakova B et al (2017) Early seizure detection based on cardiac autonomic regulation dynamics. Front Physiol 8(October):1-12. https://doi.org/10.3389/fphys.2017.00765

29. Qaraqe M, Ismail M, Serpedin E, Zulfi H (2016) Epileptic seizure onset detection based on EEG and ECG data fusion. Epilepsy Behav 58:48-60. https://doi.org/10.1016/j.yebeh.2016.02.039

30. Vandecasteele K, De Cooman T, Gu Y et al (2017) Automated epileptic seizure detection based on wearable ECG and PPG in a hospital environment. Sensors 17(2338):1-12. https://doi. org/10.3390/s 17102338

31. Boon P, Vonck K, van Rijckevorsel K et al (2015) A prospective, multicenter study of cardiac-based seizure detection to activate vagus nerve stimulation. Seizure 32:52-61. https://doi. org/10.1016/j.seizure.2015.08.011

32. Van Elmpt WJC, Nijsen TME, Griep PAM, Arends JBAM (2006) A model of heart rate changes to detect seizures in severe epilepsy. Seizure 15:366-375. https://doi.org/10.1016/j.seizu re.2006.03.005

33. Hampel KG, Vatter H, Elger CE, Surges R (2015) Cardiac-based vagus nerve stimulation reduced seizure duration in a patient with refractory epilepsy. Seizure 26:81-85. https://doi.org/10.1016/j. seizure.2015.02.004

34. Osorio I (2014) Automated seizure detection using EKG. Int J Neural Syst 24(2):1450001. https://doi.org/10.1142/S012906571 4500014

35. Varon C, Jansen K, Lagae L, Van Huffel S (2015) Can ECG monitoring identify seizures? J Electrocardiol 48(6):1069-1074. https ://doi.org/10.1016/j.jelectrocard.2015.08.020

36. Van Andel J, Ungureanu C, Arends J et al (2017) Multimodal, automated detection of nocturnal motor seizures at home: is a reliable seizure detector feasible? Epilepsia Open 2(4):424-431. https://doi.org/10.1002/epi4.12076

37. Goldenholz DM, Kuhn A, Austermuehle A et al (2017) Long-term monitoring of cardiorespiratory patterns in drug-resistant epilepsy. Epilepsia 58(1):77-84. https://doi.org/10.1111/epi.13606

38. Heldberg BE, Kautz T, Leutheuser H (2015) Using wearable sensors for semiology-independent seizure detection-towards ambulatory monitoring of epilepsy. IEEE Eng Med Biol Soc $5593-5596$ 
39. Onorati F, Regalia G, Caborni C et al (2017) Multicenter clinical assessment of improved wearable multimodal convulsive seizure detectors. Epilepsia 1:1-10. https://doi.org/10.1111/epi.13899

40. Poh MZ, Loddenkemper T, Reinsberger C et al (2012) Convulsive seizure detection using a wrist-worn electrodermal activity and accelerometry biosensor. Epilepsia 53(5):93-97. https://doi.org/ 10.1111/j.1528-1167.2012.03444.x

41. Moridani M, Farhadi H (2017) Heart rate variability as a biomarker for epilepsy seizure prediction. Bratisl Med J 118(1):3-8. https://doi.org/10.4149/BLL

42. Qaraqe M, Ismail M, Serpedin E, Zul H (2016) Epileptic seizure onset detection based on EEG and ECG data fusion. Epilepsy Behav 58:48-60. https://doi.org/10.1016/j.yebeh.2016.02.039

43. Varon C, Jansen K, Lagae L, Van Huffel S (2015) Can ECG monitoring identify seizures? J Electrocardiol 48(6):1069-1074. https ://doi.org/10.1016/j.jelectrocard.2015.08.020

44. Osorio I, Manly BFJ (2015) Probability of detection of clinical seizures using heart rate changes. Seizure 30:120-123. https://doi. org/10.1016/j.seizure.2015.06.007

45. Bernardi L, Wdowczyk-szulc J, Valenti C et al (2000) Effects of controlled breathing, mental activity and mental stress with or without verbalization on heart rate variability. J Am Coll Cardiol 35(6):1462-1469

46. Niemeijer ND, Corssmit EP, Reijntjes RH et al (2015) Sleepmediated heart rate variability after bilateral carotid body tumor resection. Sleep 38(4):633-639. https://doi.org/10.5665/sleep .4586

47. Karemaker JM (2017) An introduction into autonomic nervous function. Physiol Meas 38(5):R89-R118. https://doi. org/10.1088/1361-6579/aa6782

48. Delamont RS, Walker MC (2011) Pre-ictal autonomic changes. Epilepsy Res 97(3):267-272. https://doi.org/10.1016/j.eplepsyres .2011.10.016

49. Gilfriche P, Arsac LM, Daviaux Y et al (2018) Highly sensitive index of cardiac autonomic control based on time-varying respiration derived from ECG. Am J Physiol Regul Integr Comp Physiol 315(3):R469-R478

50. De Cooman T, Varon C, Van De Vel A et al (2018) Comparison and combination of electrocardiogram, electromyogram and accelerometry for tonic-clonic seizure detection in children. In: Proc 2018 Int Conf on Biomedical and Health Informatics, Las Vegas, NV, USA, 4-7 March 2018

51. Leijten FSS (2018) Multimodal seizure detection: a review. Epilepsia 59(S1):42-47. https://doi.org/10.1111/epi.14047

52. Cogan D, Heydarzadeh M, Nourani M (2016) Personalization of nonEEG-based seizure detection systems. IEEE Eng Med Biol Soc 6349-6352 